\title{
Compact UWB Printed Slot Antenna with Three Extra Bands and WiMAX Rejection Functionality
}

\author{
Amartya DAS $S^{1}$ Juin ACHARJEE ${ }^{2}$, Kaushik MANDAL ${ }^{1}$ \\ ${ }^{1}$ Institute of Radio Physics and Electronics, University of Calcutta, Kolkata, 700009, India \\ ${ }^{2}$ St. Thomas' College of Engineering \& Technology, Kolkata, 700023, India
}

kaushikrpe@gmail.com

Submitted February 4, 2019 / Accepted May 27, 2019

\begin{abstract}
A compact ultra-wideband (UWB) printed slot antenna with additional bands of $870-960 \mathrm{MHz}$, 1.67-1.84 GHz, 2.33-2.57 GHz for GSM-900, GSM-1800 and Bluetooth respectively along with WiMAX band rejection functionality at 3.27-4.02 GHz is presented for various wireless applications. A simple circular patch fed by a trapezoidal-shaped microstrip line is conceived to cover entire UWB (3-10.5 GHz). Three additional bands have been accommodated by incorporating two pairs of spider arm-shaped resonators at the top of the slotted ground. Coupling between the extended feed line and extended back resonator is used to acquire a stop band characteristic for the reduction of possible interference between WiMAX and UWB bands. Moreover, an arc-shaped resonator and a cross-shaped slot on the feed line are conceived to enhance the bandwidth of the UWB. The proposed design is simple in structure and compact with an overall dimension of $50 \times 50 \times 1.6 \mathrm{~mm}^{3}$, hence length is only $0.046 \lambda$ with respect to the lower edge frequency $(3 \mathrm{GHz})$ of the UWB. The simulated and measured results are in good agreement that ensures the potentiality of the proposed antenna structure for UWB and multiservice wireless applications.
\end{abstract}

\section{Keywords}

UWB, printed antenna, extra bands, band rejection, GSM-900, WiMAX

\section{Introduction}

In recent years a considerable amount of interest is focused in ultra-wideband (UWB) technologies as the Federal Communications Commission (FCC) [1] allocates the ultra-wide unlicensed $3.1-10.6 \mathrm{GHz}$ band for UWB applications. The increasing demands for wireless connectivity necessitate a single antenna to cover several useful frequency bands. Demand of multiservice microstrip antenna for portable wireless devices is forced to integrate other useful bands GSM-900 (935-960 MHz), GSM-1800 (1810-1880 MHz), and Bluetooth (2400-2500 MHz) with the UWB. Another demand for the UWB antenna design is to avoid the possible interference with the coexisting fre- quency bands WiMAX $(3.3-3.6 \mathrm{GHz})$, and WLAN $(5.15-5.35 \mathrm{GHz}, \quad 5.725-5.825 \mathrm{GHz})$. Thus, a compact UWB antenna with extra operating bands and multiband rejection characteristics is essential to fulfilling the demands of modern compact wireless devices.

Simple and compact basic UWB antennas using circular disc monopole [2], circular printed monopole with steps [3], printed slot planar inverted cone [4], and slot loaded rectangular patch [5], have been reported. To avoid the possible interference between the UWB and other coexisting frequency bands, different UWB antennas [6-11] with only band-notch characteristics are also explored to understand the effectiveness of the established methods. Printed monopole antenna [6] for UWB applications with dual band-notched has been achieved using a T-shaped slot and an inverted T-shaped parasitic structure inside the slot of the radiating patch. Variable dual band-notched has been realized by embedding two inverted U-shaped slots in the corner modified patch [7]. U-slot on the radiator along with inverted patch shaped downscaled parasitic load at the opposite end of feed line is used to achieve dual bandnotched UWB antenna [8]. Tri-band notched characteristics are achieved by introducing electrically small, capacitiveloaded loop (CLL) resonator [9], and co-directional rectangular split ring-shaped slots [10]. Metamaterial inclusions have been also proposed for filtering purpose in a UWB antenna [11]. Till date, very few works have been reported on the integration of the useful wireless bands with the UWB band along with band-notched characteristic. An Lshaped strip is connected to the monopole radiator [12] to accommodate an extra Bluetooth band. A modified meandered shaped stub to create an extra Bluetooth band and a quadratic fractal slot on the radiator to achieve a single band notched, results in a complicated fractal shaped UWB antenna [13]. Further, a triangular shaped patch, an Lshaped ground plane and a tapered microstrip feed line [14] have been conceived to accommodate extra Bluetooth band along with a single band notched. In [15], a quarter-wavelength stub is attached to the ground plane to create an extra Bluetooth band and also two similar stubs are used to create dual notch bands. A Fibonacci type GSM-UWB band antenna [16] with triple band-notched characteristics and integrated GSM band functionality has been proposed 


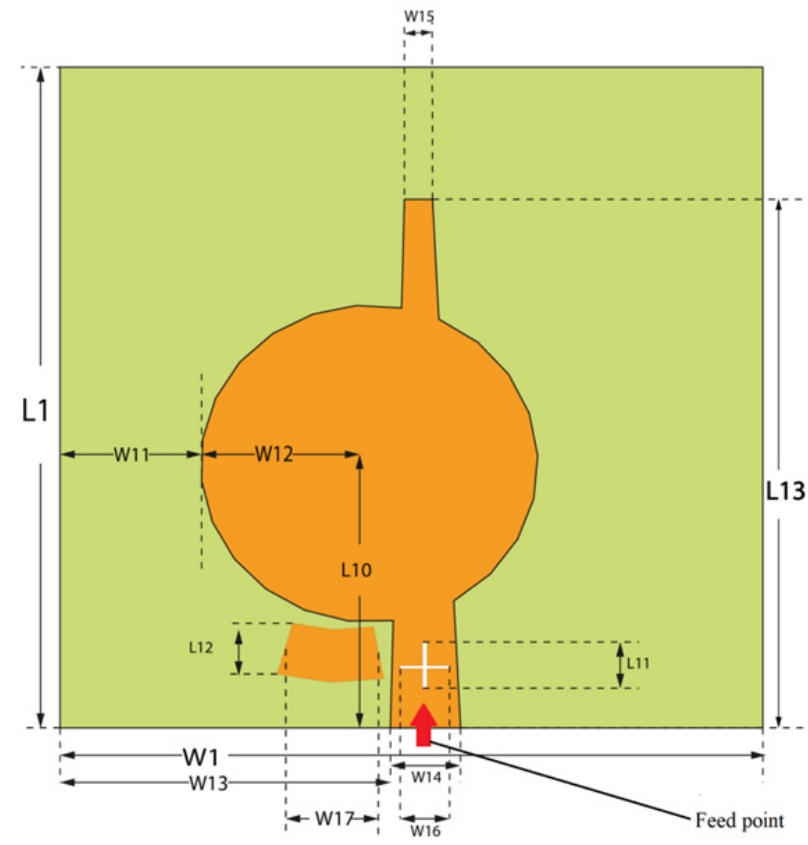

(a)

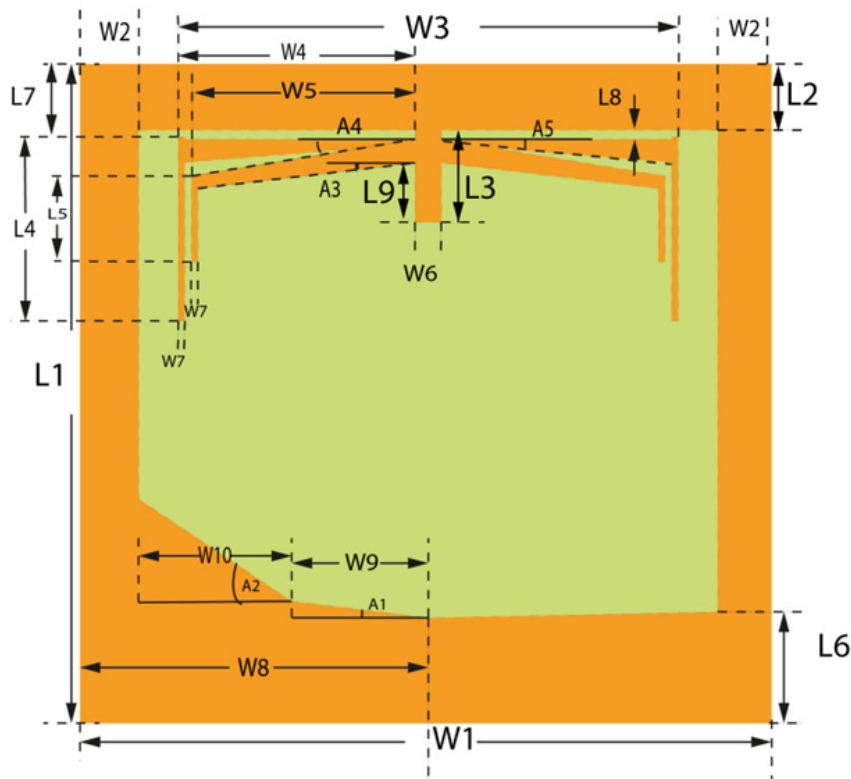

(b)

Fig. 1. Proposed antenna structures: (a) top view, and (b) bottom view.

by Srivastava et al. An approximate trapezoidal spiral for Bluetooth application and rectangular resonant spiral structures for rejection of quadruple frequency bands are conceived with a semi elliptical planar monopole [17]. In all the previous cases the number of the extra band is only one and number of notch-band ranges from zero to four. In [18], three bands Bluetooth, GSM, and GPS have been added along with the UWB by using inverted U-shaped strips at the upper part of the slotted ground. However, this design was unable to provide any band-notch characteristic. Therefore, the design of a UWB antenna with extra operating bands and multiband rejection characteristics is still a challenging task for the antenna designer.

In this paper, a compact UWB printed slot antenna with three additional bands and a notch band is presented. This antenna is designed to achieve a $-10 \mathrm{~dB}$ impedance bandwidth ranging from 0.9 to $10.3 \mathrm{GHz}$, convenient for multiple wireless applications. The proposed design is operated on the GSM-900, GSM-1800, Bluetooth and UWB bands with a band-notch characteristic covering the WiMAX band. All the simulations are carried out using FEM-based Ansys HFSS EM simulator. Antenna design concepts and the structure are described in Sec. 2. The simulated results are validated in Sec. 3 and finally, concluding remarks are presented in Sec. 4.

\section{Antenna Design and Configuration}

The basic antenna configuration is shown in Fig. 1. It consists of a circular radiating patch, a trapezoidal shaped microstrip feed line, and a slotted ground plane. The antenna is printed on a $50 \mathrm{~mm} \times 50 \mathrm{~mm}$ FR4 substrate of thickness $\mathrm{h}=1.6 \mathrm{~mm}$, permittivity $\varepsilon_{\mathrm{r}}=4.4$ and loss tangent of 0.02 . The antenna is fed by a trapezoidal shaped micro- strip line of $5 \mathrm{~mm}$ width near the feeding point and $2 \mathrm{~mm}$ at the top and a length of $40 \mathrm{~mm}$ for better impedance matching [19]. The feed line is running through the patch of radius $12 \mathrm{~mm}$ centered at $(22,20,1.6)$.

The basic ground plane is modified by introducing a big slot considering the two side walls of width $3 \mathrm{~mm}$, top wall of width $5 \mathrm{~mm}$, and a protruding triangle of height $8 \mathrm{~mm}$ and base of $39.3 \mathrm{~mm}$ is also made adjacent to the lower wall to support multiple frequencies. Moreover, two pairs of spider arm-shaped resonators [18] in the top of the slotted ground are also introduced to achieve extra bands. Further, an arc-shaped resonator of width $3 \mathrm{~mm}$ and a cross-shaped slot on the feed line are used to enhance the bandwidth of the UWB. This resonator starts from $(16,6$, 1.6) and ends at $(20,20,1.6)$ with an angle of $26.5^{\circ}$.

For better impedance matching and to optimize the various dimensions of the proposed antenna a large number of simulations have been carried out. The optimal dimensions of the proposed antenna parameters are as follows: $\{W 1=50 \mathrm{~mm}, W 2=3 \mathrm{~mm}, W 3=38 \mathrm{~mm}, W 4=14.4 \mathrm{~mm}$, $W 5=14 \mathrm{~mm}, W 6=2 \mathrm{~mm}, W 7=0.5 \mathrm{~mm}, W 8=25 \mathrm{~mm}$, $W 9=10.3 \mathrm{~mm}, \quad W 10=11.7 \mathrm{~mm}, W 11=10 \mathrm{~mm}, \quad W 12=$ $12 \mathrm{~mm}, \quad W 13=23.5 \mathrm{~mm}, W 14=5 \mathrm{~mm}, W 15=2 \mathrm{~mm}$, $W 16=3.5 \mathrm{~mm}, W 17=14 \mathrm{~mm}, L 1=50 \mathrm{~mm}, L 2=5 \mathrm{~mm}$, $L 3=7 \mathrm{~mm}, L 4=14 \mathrm{~mm}, L 5=6 \mathrm{~mm}, L 6=8 \mathrm{~mm}, L 7=$ $5.5 \mathrm{~mm}, L 8=0.6 \mathrm{~mm}, L 9=4.5 \mathrm{~mm}, L 10=20 \mathrm{~mm}, L 11=$ $3.5 \mathrm{~mm}, L 12=13 \mathrm{~mm}, L 13=40 \mathrm{~mm}, A 1=9^{\circ}, A 2=18^{\circ}$, $A 3=34^{\circ}, A 4=25^{\circ}$, and $\left.A 5=18^{\circ}\right\}$.

\subsection{Design Steps}

An asymmetrically fed circular patch [2] type monopole structure is considered as the reference antenna (A), as shown in Fig. 2(a). The feed line is selected as trapezoidal 


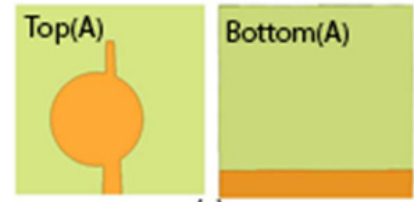

(a)

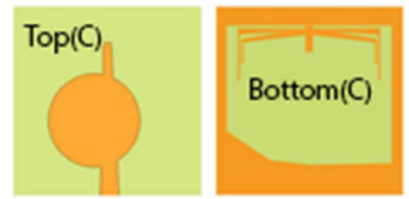

(c)

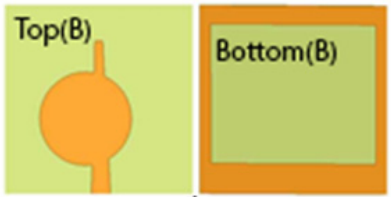

(b)

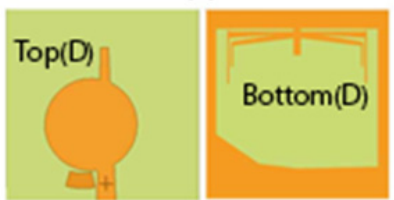

(d)
Fig. 2. Evolution of the proposed antenna structure: (a) Antenna-A, (b) Antenna-B, (c) Antenna-C, and (d) Proposed.

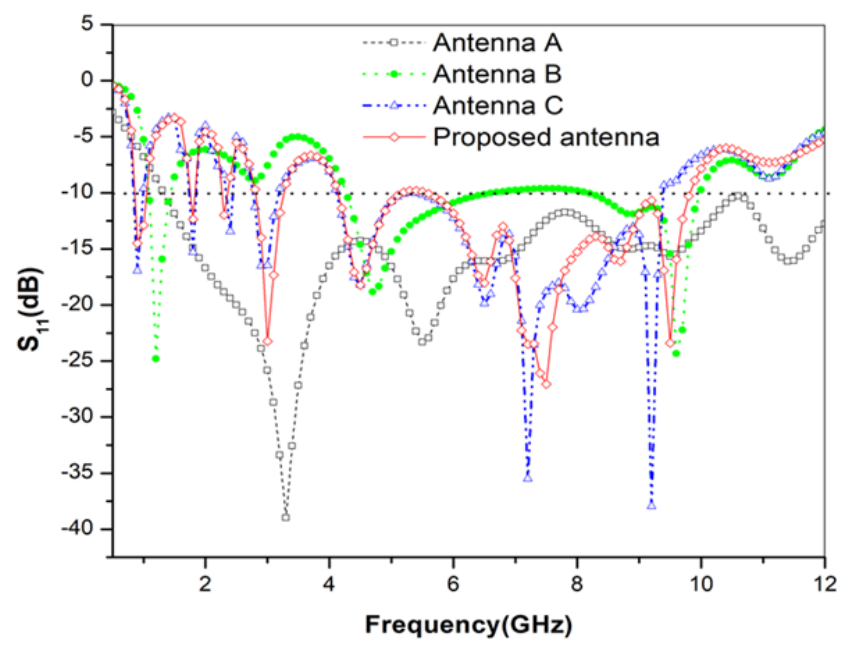

Fig. 3. Stepwise improvement of reflection coefficient $\left(\mathrm{S}_{11}\right)$.

shaped [19] in structure to provide better impedance matching at the additional bands. A simple ground of length of $8 \mathrm{~mm}$ is considered. The circular monopole provides an ultra-wideband bandwidth $1.4-12 \mathrm{GHz}$, as shown in Fig. 3. Now to accommodate extra bands the concept of background resonators [18] has been conceived. Coupling between the resonators is a useful technique to increase the bandwidth [20]. Thus the two sides of the ground are extended and joined at the top. This configuration is named as antenna-B and shown in Fig. 2(b). This ground modification provides an extra band which is later finely tuned to the desired frequency bands. The corresponding reflection coefficient $\left(\mathrm{S}_{11}\right)$ is shown in Fig. 3.

To get two more extra bands the ground is modified further by adding two pairs of spider arm-shaped resonators. This configuration is termed as antenna-C and shown in Fig. 2(c). This design provides three extra bands along with a stop band over $3.18-4.12 \mathrm{GHz}$ which is mainly due to the coupling between the extended feed line and extended back resonator. However, the bandwidth of UWB is reduced and it only covers $2.9-8.1 \mathrm{GHz}$, as shown in Fig. 3.

A cross-shaped slot is introduced on the feed line and an arc-shaped resonator is used to enhance the bandwidth of the UWB. This design is optimized to get the desired results and termed as the proposed antenna (antenna-D) as

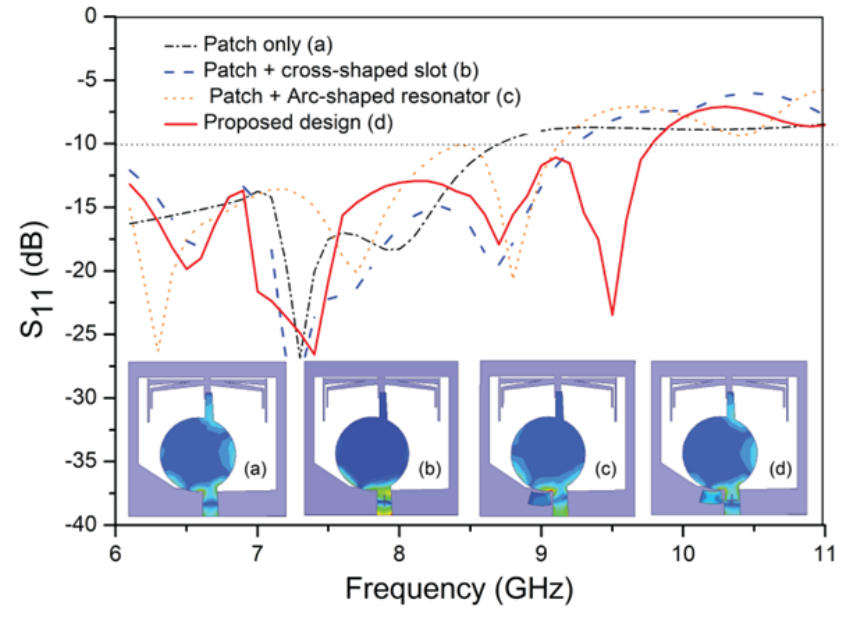

Fig. 4. Effects of cross-shaped slot and an arc-shaped resonator, on the surface current distributions (@) $9 \mathrm{GHz}$ ) and $\mathrm{S}_{11}$ plots.

shown in Fig. 2(d). The proposed design is operated over the UWB (2.81-9.8 GHz) along with three extra bands GSM-900 (0.85-1.03 GHz), GSM-1800 (1.72-1.83 GHz), Bluetooth (2.33-2.48 GHz) and a notch at the WiMAX $(3.18-4.12 \mathrm{GHz})$ band. This is summarized in Fig. 3. Further, to explain the function of cross-shaped slot and an arc-shaped resonator, the surface current distributions and comparative $S_{11}$ plots for different design steps are shown in Fig. 4. The design (Fig. 4a) without any slot and resonator is unable to cover the upper edge frequencies of UWB and surface current $(@ 9 \mathrm{GHz})$ is distributed randomly throughout the patch. The cross-shaped slot (Fig. 4b) helps to increase the current distribution along the feed-line and the BW also increases slightly. Considering the possible coupling with the feed line, an arc-shaped resonator is introduced (Fig. 4c), but the resonator alone is not able to cover the upper edge frequencies of the UWB. This is because without the cross-shaped slot current concentration is lower on the feed line. So, the arc-shaped resonator in presence of the cross-shaped slot provides better coupling due to the higher current concentration on the feed line. The dimension of the arc-shaped resonator is chosen in such a way so that it resonates around 9.5-10 GHz and staggered with the higher resonances of the patch thereby able to cover the entire UWB band. Hence due to the introduction of cross-shaped slot and an arc-shaped resonator better impedance matching has been realized near the higher cut-off frequency of the UWB and the higher edge frequency $(8.1 \mathrm{GHz})$ has been shifted to $9.8 \mathrm{GHz}$.

\subsection{Parametric Study}

In order to optimize the patch radius $(R)$, it has been varied from $11 \mathrm{~mm}$ to $13 \mathrm{~mm}$ and the corresponding reflection coefficients $\left(\mathrm{S}_{11}\right)$ are shown in Fig. 5. It is found that for $R=12 \mathrm{~mm}$ the impedance matching is better over the entire UWB. The side walls width $(W 2)$ of the slotted ground is also an important parameter to optimize the position of the first operating band covering the GSM-900 band. The width is varied from $2 \mathrm{~mm}$ to $4 \mathrm{~mm}$ and the cor- 


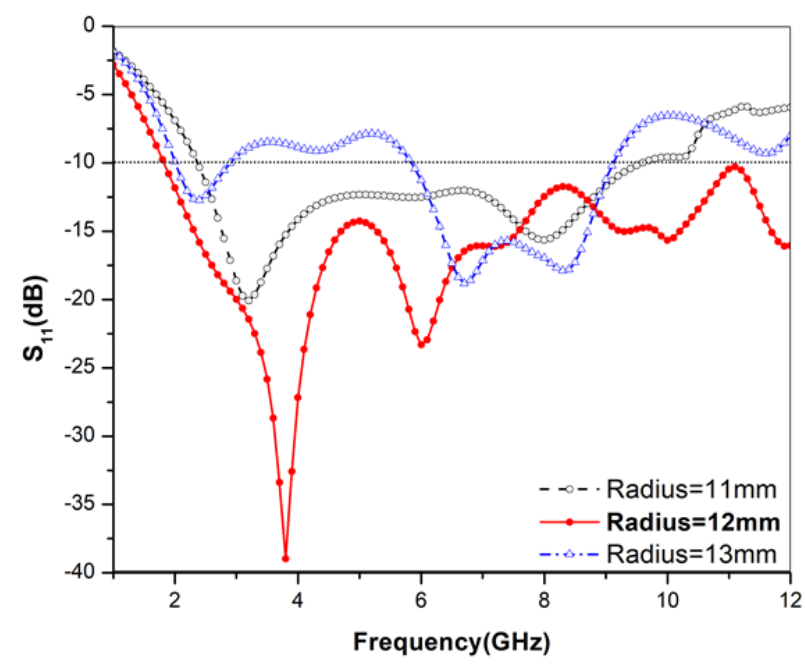

Fig. 5. Change in $S_{11}$ characteristics due to radius variation of circular patch.

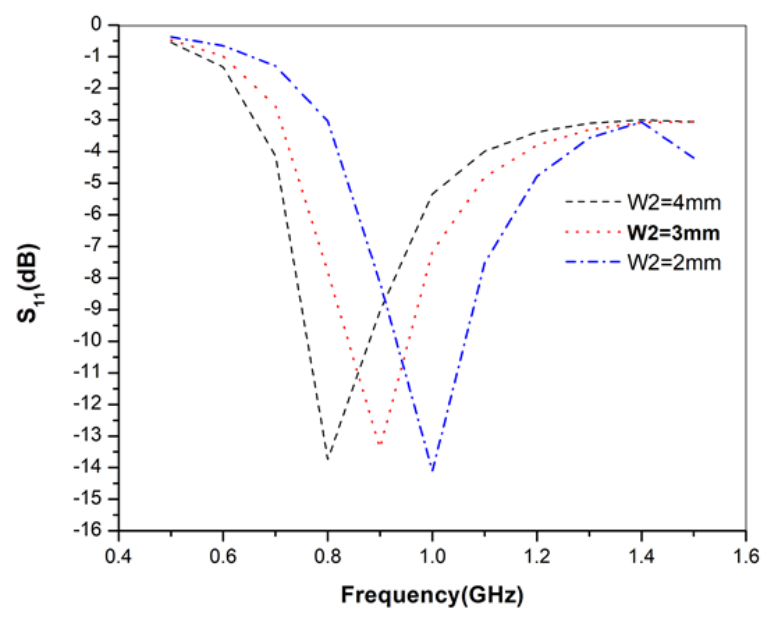

Fig. 6. $S_{11}$ characteristics for the GSM-900 band due to side wall width variation of the ground plane.

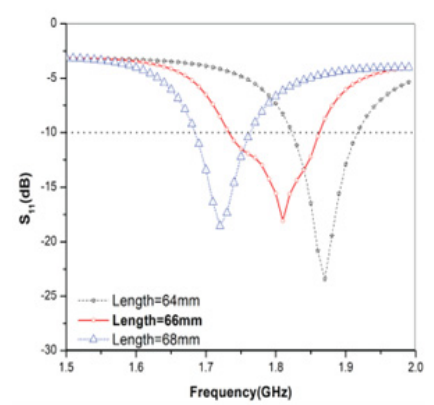

(a)

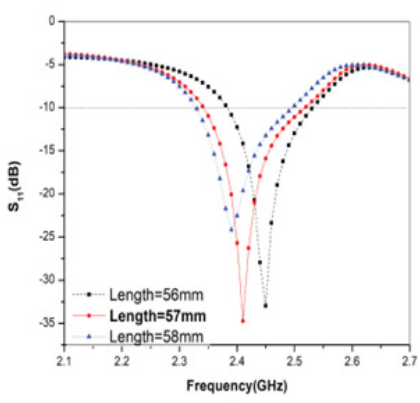

(b)
Fig. 7. $\mathrm{S}_{11}$ characteristics for the (a) GSM-1800, and (b) Bluetooth bands, due to length variation of the spider arm-shaped resonators.

responding $\mathrm{S}_{11}$ (only for the first band) is summarized in Fig. 6. It has been observed that for $W 2=3 \mathrm{~mm}$, the operating band covers the entire GSM-900 band with resonating frequency at $900 \mathrm{MHz}$.

The overall length of two spider arm-shaped resonators has been varied to optimize the position of the two additional operating bands so that they can cover the entire

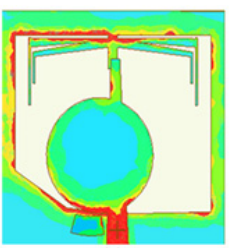

(a)

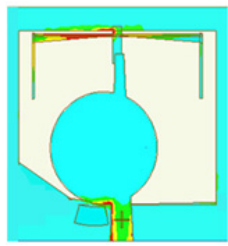

(b)

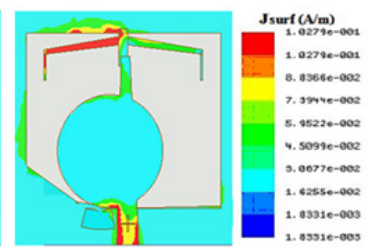

(c)
Fig. 8. Surface current distributions at three resonant frequencies: (a) $900 \mathrm{MHz}$, (b) $1.8 \mathrm{GHz}$, (c) $2.4 \mathrm{GHz}$.

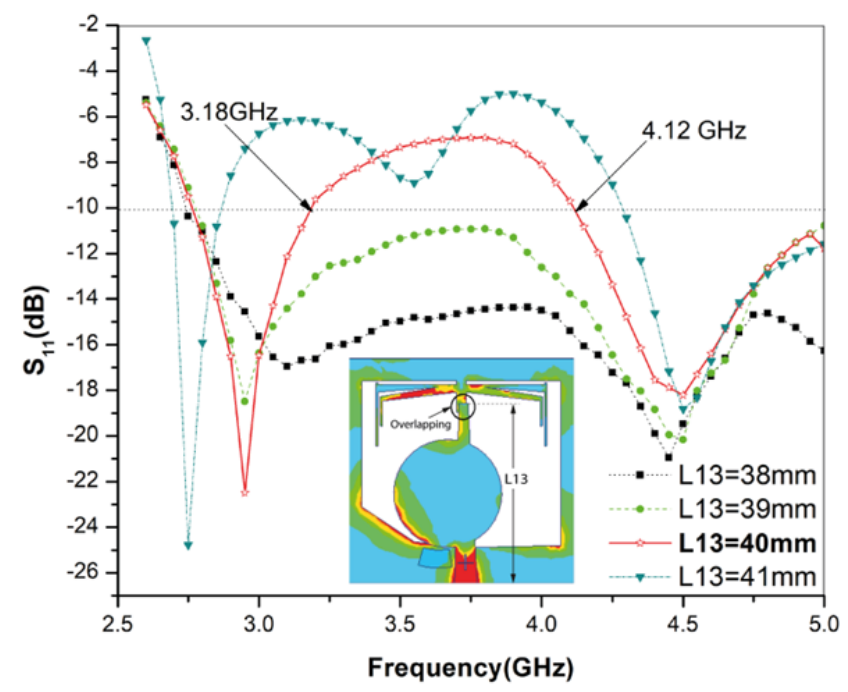

Fig. 9. Confirmation of stop band characteristic due to length variation of feed line.

GSM-1800 and Bluetooth bands exactly. The larger resonator arms with length $64 \mathrm{~mm}$ to $68 \mathrm{~mm}$ provide variable operating band centered at $1.8 \mathrm{GHz}$. Similarly, the variation of smaller arm's length from $56 \mathrm{~mm}$ to $58 \mathrm{~mm}$ exhibits a resonance at $2.4 \mathrm{GHz}$. These are illustrated in Fig. 7(a) and Fig. 7(b), respectively. The larger and smaller arm's length is optimized at $66 \mathrm{~mm}(\lambda / 2.6)$, and $57 \mathrm{~mm}(\lambda / 2.48)$ respectively, where $\lambda$ is the wavelength corresponding to the individual resonance frequency. The dimensions of the resonators are considered such that its resonance frequency is close to that of the modified ground. Thus, coupling among multiple resonances provides a wide bandwidth $(>500 \mathrm{kHz})$ for each extra operating bands (GSM-900, GSM-1800, and Bluetooth).

The surface current densities at three resonant frequencies of the extra bands have been illustrated in Fig. 8 . It is evidence that the two side walls of the ground, larger spider arm-shaped resonator, and smaller spider armshaped resonator are responsible for the GSM-900, GSM1800 , and Bluetooth bands respectively. Due to the asymmetric nature of the patch (inclined more towards the lefthand side); the mutual coupling is more with the left arm of the ground plane. Hence, the surface current density is also more to the left arm than the right arm of the ground plane.

As discussed in the design steps that the overlapping between the extended feed line and the extended back resonator is responsible for the stop band characteristic. The parametric study of feed line length variation is confirming the same. With the change in length $(L 13)$ of the extended 


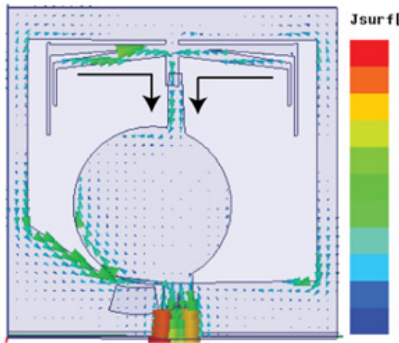

(a)

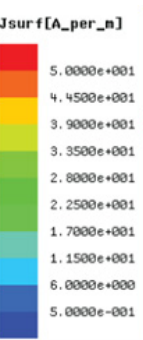

$.00000-001$

Fig. 10. Vector plots of surface current distributions at (a) $3.5 \mathrm{GHz}$, and (b) $8.2 \mathrm{GHz}$.

feed line the stop band is affected and the length has been optimized at $40 \mathrm{~mm}$ for the band notch functionality over 3.18-4.12 GHz. This is shown in Fig. 9, and the surface current distribution at the center frequency $(3.5 \mathrm{GHz})$ of the notch band is also shown in the inset of this figure. The vector plots of surface current distributions at $3.5 \mathrm{GHz}$, and 8.2 GHz (out of notch band) are shown in Fig. 10(a) and Fig. 10(b), respectively. It shows that at the center frequency of the notch band the extended ground and patch acts as a single unit. Hence, they are shorted and no radiation takes place in the far-field as the field lines originating at the patch and ends in the ground. Whereas, at out of the notch band the direction of current flow on the extended feed line and extended back resonator is in the opposite direction.

\section{Measured Results and Discussions}

In order to realize the improved performance of the proposed antenna, the dimensions of the geometrical parameters are chosen from the parametric studies of the antenna as described in Sec. 2. The proposed antenna is fabricated for experimental verifications. The measured and simulated frequency responses of the reflection coefficient $\left(\mathrm{S}_{11}\right)$ for the proposed antenna are shown in Fig. 11. Photos of the fabricated prototype are shown in the inset of Fig. 11. The measured impedance bandwidth, defined by $\mathrm{S}_{11} \leq-10 \mathrm{~dB}$, covers the GSM-900 (870-960 MHz), GSM1800 (1.67-1.84 GHz), Bluetooth (2.33-2.57 GHz), and entire UWB (3-10.5 GHz). The measured result shows a sharp band notched, covering the WiMAX (3.27 to $4.02 \mathrm{GHz}$ ) band. The comparison shows that the measured result reasonably agrees with the simulated result throughout the operating bands. The alignment of different arms, slots, and resonators may be the main reason for fabrication tolerances. The low-cost SMA connector contributes to conductor loss in the practically implemented antenna. Hence, fabrication tolerances and low-cost SMA may be responsible for the slight mismatch between the measured and simulated $S_{11}$ plots. Considering the difficulties to implement such a compact antenna, this amount of mismatch can be accepted as an encouragement.

The measured E-plane and H-plane far-field normalized radiation patterns at $0.9 \mathrm{GHz}, 1.8 \mathrm{GHz}, 2.4 \mathrm{GHz}$, 4.58 GHz, and $9.55 \mathrm{GHz}$ are shown in Fig. 12(a), (b), and Fig. 13(a), (b), (c), respectively.

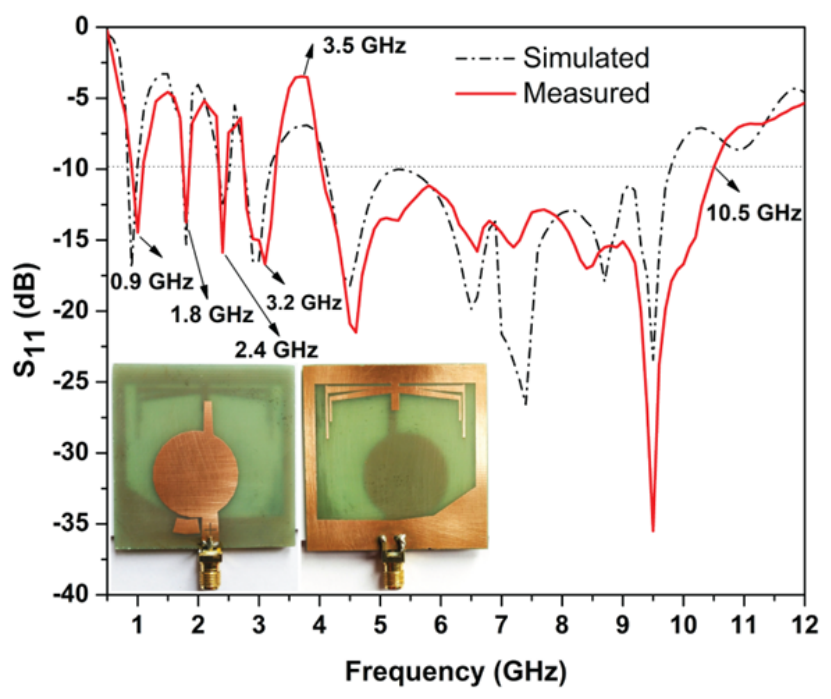

Fig. 11. Simulated and measured $S_{11}$ characteristics for the proposed antenna.
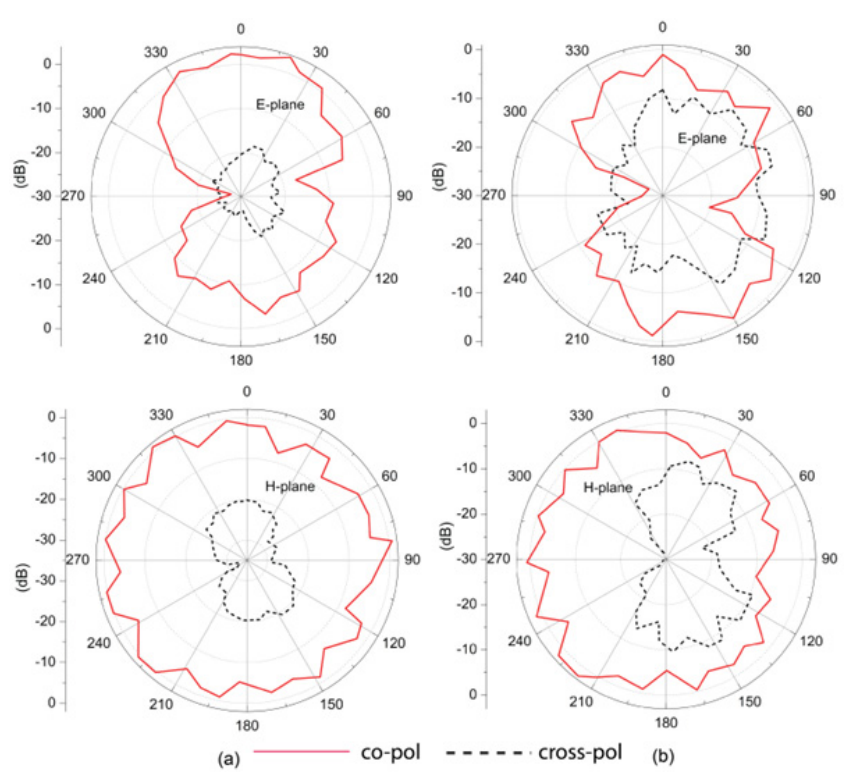

Fig. 12. Measured radiation patterns (a) $0.9 \mathrm{GHz}$, (b) $1.8 \mathrm{GHz}$.

The simulated and measured peak gain and the simulated efficiency of the proposed antenna are shown in Fig. 14. At notch band, the peak gain and efficiency falls remarkably and in the UWB region, the gain is sufficiently high. The maximum realized peak gain is $3.8 \mathrm{dBi}$ at $6.5 \mathrm{GHz}$ and the maximum efficiency is $91.15 \%$ at $5.5 \mathrm{GHz}$. With the dimension of approximately $0.046 \lambda \times 0.046 \lambda$, the area of illumination is least for $0.9 \mathrm{GHz}$ followed by $1.8 \mathrm{GHz}$ and $2.4 \mathrm{GHz}$. Thus the gain is lower for the corresponding lower frequency bands.

To enlighten the advantages of the proposed design over the previously published designs of its class, a comparative study is carried out and summarized in Tab. 1 . In [13] and [15] the UWB antennas with notch band characteristic have been able to accommodate a single extra band only. The UWB antenna [16] successfully accommodates three extra bands but fails to include a single notch band. The overall dimension of the proposed antenna is also 


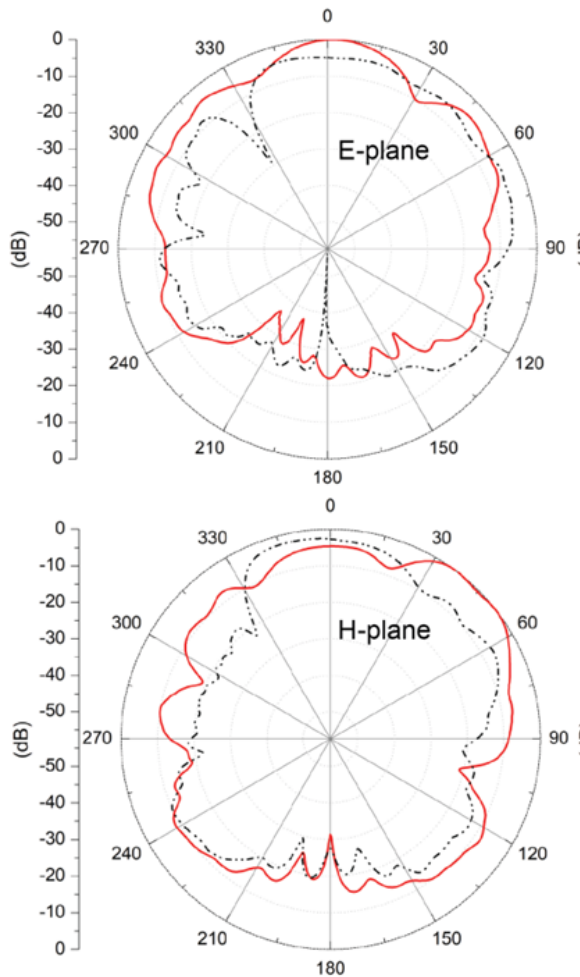

(a)
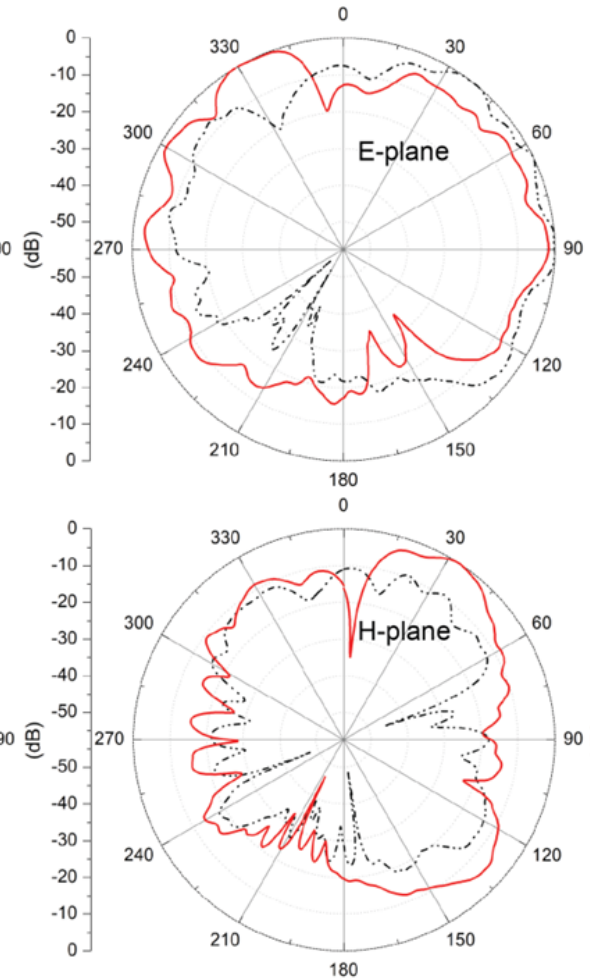

(b)
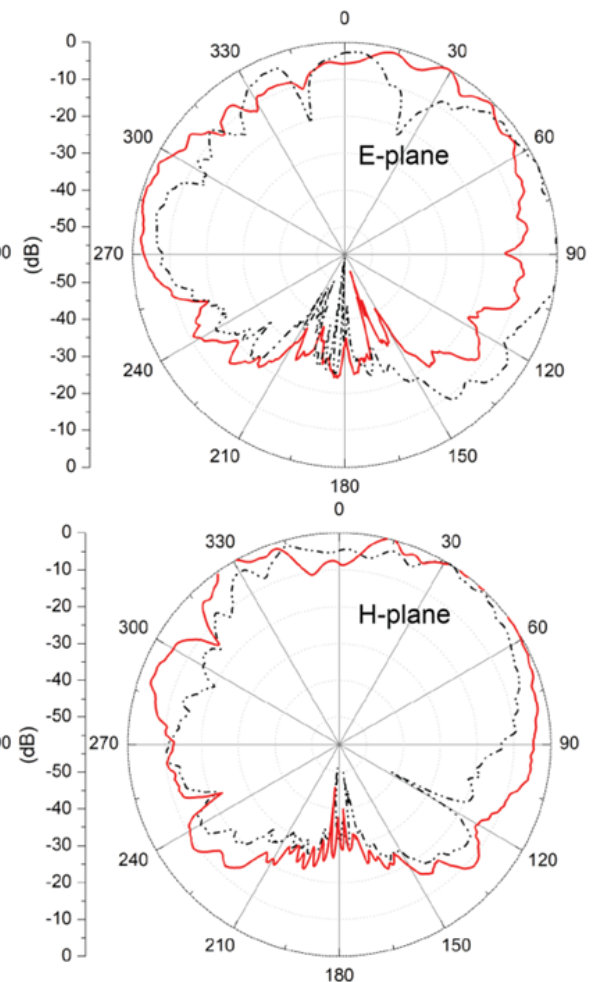

(c)

Fig. 13. Measured radiation patterns (a) $2.4 \mathrm{GHz}$, (b) $4.58 \mathrm{GHz}$, and (c) $9.55 \mathrm{GHz}$.

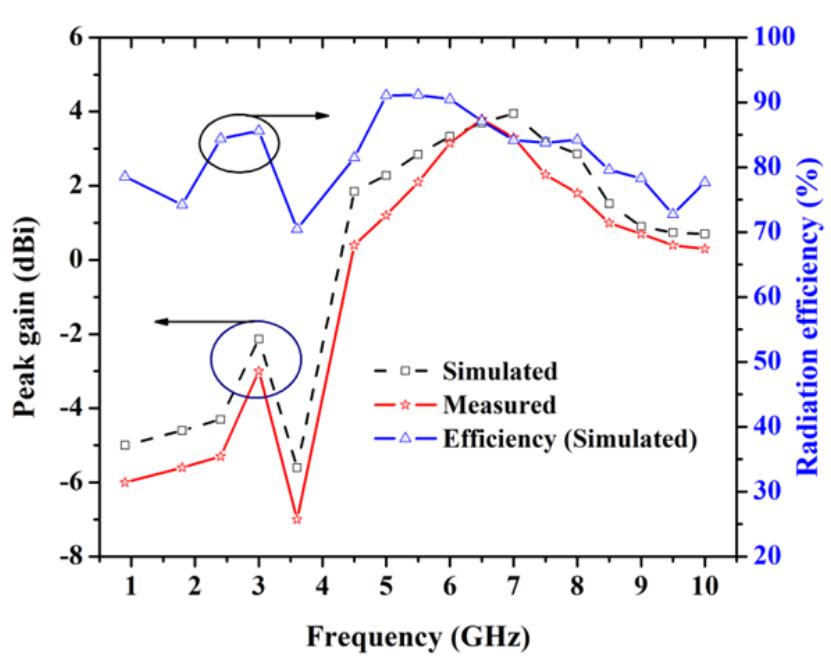

Fig. 14. Measured and simulated peak gain variation, and simulated radiation efficiency variation.

lower or of the order of other antennas of its class. So, the proposed design is able to cross the design hurdle of compact UWB antenna design for multiple wireless services along with band rejection functionality. Realizing Bluetooth band along with UWB is the necessity for wireless personal area network (WPAN) applications. On the other hand, realizing Bluetooth and GSM in a single antenna, makes the design suitable for mobile phones also. Further, there is a possibility to allocate different transmitting power for the different transmitting bands by using separate modulator and amplifier circuits for the individual bands.

\begin{tabular}{|c|c|c|c|c|}
\hline $\begin{array}{l}\text { Related } \\
\text { works }\end{array}$ & Size & $\begin{array}{l}\text { Operating } \\
\text { bands }\end{array}$ & $\begin{array}{l}\text { Peak } \\
\text { gain } \\
\text { (dBi) }\end{array}$ & $\begin{array}{l}\text { Notch } \\
\text { band }\end{array}$ \\
\hline \multirow{2}{*}{ [13] } & \multirow{2}{*}{$\begin{array}{c}23 \mathrm{~mm} \times 28 \mathrm{~mm} \\
(0.026 \lambda \times 0.032 \lambda)\end{array}$} & $2.4 \mathrm{GHz}$ & -5 & \multirow{2}{*}{$\begin{array}{l}3.5 \mathrm{GHz}, \\
5.8 \mathrm{GHz}\end{array}$} \\
\hline & & UWB & $\approx 4$ & \\
\hline \multirow{2}{*}{ [15] } & \multirow{2}{*}{$\begin{array}{l}18.5 \mathrm{~mm} \times 39 \mathrm{~mm} \\
(0.019 \lambda \times 0.040 \lambda)\end{array}$} & $2.4 \mathrm{GHz}$ & 3 & \multirow{2}{*}{$3.5 \mathrm{GHz}$} \\
\hline & & UWB & 5.8 & \\
\hline \multirow{4}{*}{ [16] } & \multirow{4}{*}{$\begin{array}{c}54 \mathrm{~mm} \times 55 \mathrm{~mm} \\
(0.055 \lambda \times 0.056 \lambda)\end{array}$} & $1.5 \mathrm{GHz}$ & -6 & \multirow{4}{*}{ Nil } \\
\hline & & $1.8 \mathrm{GHz}$ & - & \\
\hline & & $2.4 \mathrm{GHz}$ & -4 & \\
\hline & & UWB & 2.5 & \\
\hline \multirow{4}{*}{ Proposed } & \multirow{4}{*}{$\begin{array}{c}50 \mathrm{~mm} \times 50 \mathrm{~mm} \\
(0.046 \lambda \times 0.046 \lambda)\end{array}$} & $0.9 \mathrm{GHz}$ & -6 & \multirow{4}{*}{$3.5 \mathrm{GHz}$} \\
\hline & & $1.8 \mathrm{GHz}$ & -5.6 & \\
\hline & & $2.4 \mathrm{GHz}$ & -5.3 & \\
\hline & & UWB & 3.8 & \\
\hline
\end{tabular}

Tab. 1. Comparison of the proposed antenna performances with some previous related works.

\section{Conclusion}

A compact printed slot antenna for UWB and multiple wireless applications along with single band rejection functionality is proposed, fabricated and validated with the experimental data. This antenna is able to avoid the interferences with WiMAX (3.27-4.02 GHz) band. In comparison to the related articles, this antenna provides UWB plus 
a maximum number of extra bands along with single band rejection functionality. Side walls of the slotted ground and the length of spider arm shaped back resonators are crucial to adjust the band and center frequency of the additional bands. Amount of overlapping between the extended trapezoidal shaped feed line and extended back resonators play the important role to adjust the notch band. Stable radiation patterns and acceptable gain make this antenna attractive for UWB applications along with GSM-900, GSM-1800, and Bluetooth services.

\section{Acknowledgments}

The authors would like to acknowledge Prof. Partha Pratim Sarkar, Department of Engineering \& Technological Studies, University of Kalyani, West Bengal, India, and Dr. Satyajit Chakrabarti, Society for Applied Microwave Electronics Engineering \& Research (SAMEER), Kolkata, India for providing measurement facilities.

\section{References}

[1] FEDERAL COMMUNICATIONS COMMISSION. Federal Communication Commission Revision of Part 15 of Commission's Rules Regarding Ultra-wideband Transmission Systems. First Report and Order FCC, 02. V48, Washington, DC, USA, 2002.

[2] LIANG, J., CHIAU, C. C., CHEN, X., et al. Printed circular disc monopole antenna for ultra-wideband applications. Electronics Letters, 2004, vol. 40, p. 1246-1247. DOI: 10.1049/el:20045966

[3] AHMED, O., SEBAK, A. R. A printed monopole antenna with two steps and a circular slot for UWB applications. IEEE Antennas and Wireless Propagation Letters, 2008, vol. 7, p. 411-413. DOI: 10.1109/LAWP.2008.2001026

[4] CHENG, S., HALlBJÖRNER, P., RYDBERG, A. Printed slot planar inverted cone antenna for ultra-wideband applications. IEEE Antennas and Wireless Propagation Letters, 2008, vol. 7, p. 18-21. DOI: 10.1109/LAWP.2007.914115

[5] MISHRA, R., JAYASINGHE, J., MISHRA, R. G., et al. Design and performance analysis of a rectangular microstrip line feed ultra-wide band antenna. International Journal of Signal Processing, Image Processing and Pattern Recognition, 2016, vol. 9, no. 6, p. 419-426. DOI: 10.14257/ijsip.2016.9.6.36

[6] OJAROUDI, N., OJAROUDI, M. Novel design of dual bandnotched monopole antenna with bandwidth enhancement for UWB applications. IEEE Antennas and Wireless Propagation Letters, 2013, vol. 12, p. 698-701. DOI: 10.1109/LAWP.2013.2264713

[7] ACHARJEe, J., MANDAL, K., MANDAL, S. K., et al. A compact printed monopole antenna with enhanced bandwidth and variable dual band notch for UWB applications. Journal of Electromagnetic Waves and Applications, 2016, vol. 60, p. $1980-1992$. DOI: $10.1080 / 09205071.2016 .1234419$

[8] KUNDU, S., CHATTERJEE, A., JANA, S. K., et al. A high gain dual notch compact UWB antenna with minimal dispersion for ground penetrating radar application. Radioengineering, 2018, vol. 27 , no. 4, p. 990-997. DOI: $10.13164 /$ re. 2018.0990

[9] LIN, C., JIN, P., ZIOLKOWSKI, R. Single, dual and tri-bandnotched ultra-wideband (UWB) antennas using capacitively loaded loop (CLL) resonators. IEEE Transactions on Antennas and Propagation, 2012, vol. 60 , no. 1, p. 102-109. DOI: 10.1109/TAP.2011.2167947
[10] KUNDU, S., JANA, S. K. Leaf-shaped CPW-fed UWB antenna with triple notch bands for ground penetrating radar applications. Microwave and Optical Technology Letters, 2018, vol. 60, no. 4, p. $930-936$. DOI: $10.1002 /$ mop. 31075

[11] KAHNG, S., SHIN, E. C., JANG, G. H., et al. A UWB antenna combined with the CRLH metamaterial UWB bandpass filter having the bandstop at the $5 \mathrm{GHz}-$ band WLAN. In IEEE Antennas and Propagation Society International Symposium. Charleston (SC, USA), June 2009. DOI: 10.1109/APS.2009.5172114

[12] YILDIRIM, B. S., CETINER, B. A., ROQUETA, G., et al. Integrated Bluetooth and UWB antenna. IEEE Antennas and Wireless Propagation Letters, 2009, vol. 8, p. 149-152. DOI: 10.1109/LAWP.2009.2013371

[13] GORAI, A., PAL, M., GHATAK, R. A compact fractal-shaped antenna for ultra-wideband and Bluetooth wireless systems with WLAN rejection functionality. IEEE Antennas and Wireless Propagation Letters, 2017, vol. 16, p. 2163-2166. DOI: 10.1109/LAWP.2017.2702208

[14] YADAV, S., GAUTAM, A. K., KANAUJIA, B. K., et al. Design of band-rejected UWB planar antenna with integrated Bluetooth band. IET Microwaves, Antennas and Propagation, 2016, vol. 10, no. 14 , p. $1528-1533$. DOI: 10.1049 /iet-map. 2016.0118

[15] SAMADI TAHERI, M. M., HASSANI, H. R., NEZHAD, S. M. A. UWB printed slot antenna with Bluetooth and dual notch bands. IEEE Antennas and Wireless Propagation Letters, 2011, vol. 10, p. 255-258. DOI: 10.1109/LAWP.2011.2119391

[16] SRIVASTAVA, K., KUMAR, A., KANAUJIA, B. K., et al. Integrated GSM-UWB Fibonacci-type antennas with single, dual, and triple notched bands. IET Microwaves, Antennas and Propagation, 2018, vol. 12, no. 6, p. 1004-1012. DOI: 10.1049/iet-map.2017.0074

[17] REDDY, G. S., KAMMA, A., MISHRA, S. K., et al. Compact Bluetooth/UWB dual-band planar antenna with quadruple bandnotch characteristics. IEEE Antennas and Wireless Propagation Letters, 2014, vol. 13, p. 872-875. DOI: 10.1109/LAWP.2014.2320892

[18] BOD, M., HASSANI, H. R., SAMADI TAHERI, M. M. Compact UWB printed slot antenna with extra Bluetooth, GSM and GPS bands. IEEE Antennas and Wireless Propagation Letters, 2012, vol. 11, p. 531-534. DOI: 10.1109/LAWP.2012.2197849

[19] CHANDEL, R., GAUTAM, A. K., RAMBABU, K. Tapered fed compact UWB MIMO-diversity antenna with dual band-notched characteristics. IEEE Transactions on Antennas and Propagation, 2018 , vol. 66, no. 4, p. 1677-1684. DOI: 10.1109/TAP.2018.2803134

[20] RisCO, S., ANGUERA, J., ANDÚJAR, A., et al. Coupled monopole antenna design for multiband handset devices. Microwave and Optical Technology Letters, 2010, vol. 52, no. 2, p. 359-364. DOI: $10.1002 /$ mop. 24893

\section{About the Authors ...}

Amartya DAS received his B.Tech. degree in Electronics and Communication Engineering from the Future Institute of Engineering and Management, West Bengal, India, in 2015 under the affiliation of former West Bengal University of Technology and the M. Tech. degree in Radio Physics and Electronics from the Institute of Radio Physics and Electronics, University of Calcutta, West Bengal, India in 2018. His current research interests include the design and analysis of multiband microstrip patch antenna, and printed antenna for the UWB applications. 
Juin ACHARJEE received her B. Tech degree and M. Tech degree in Electronics and Communication Engineering from the Maulana Abul Kalam Azad University of Technology (MAKAUT), West Bengal, India, in 2010, and 2013 respectively. She is currently pursuing her $\mathrm{Ph}$.D. from the National Institute of Technology, Durgapur, West Bengal, India. From October 2018 she is working as an Assistant Professor in the Department of Electronics and Communication Engineering, St. Thomas College of Engineering and Technology, West Bengal, India. Her research interest includes characterization of defective ground structure (DGS) and their applications in performance enhancement of microstrip antenna, and design and analysis of compact UWB antenna.

Kaushik MANDAL received his B. Sc degree in Physics (H), B. Tech and M. Tech degree in Radio Physics and Electronics from the University of Calcutta, in 2001, 2004 and 2006 respectively. He received his Ph.D. (Tech.) from the University of Kalyani, in July 2014. From 2016 he is working as an Assistant Professor in the Institute of Radio Physics and Electronics, University of Calcutta, West Bengal, India. He has authored or co-authored over 30 internationally refereed journal and conference papers. His current research interests include the characterization and application of DGS, antennas for RF energy harvesting system, SIW integrated microstrip antenna, and performance enhancement of microstrip antenna using frequency selective surface (FSS). Dr. Mandal is a co-recipient of the IEEE TENCON 2017 Best Paper Award (in the track 'Antenna'). Dr. Mandal is an active reviewer of IEEE Transactions on Antennas and Propagation, IEEE Antennas and Propagation Magazine, IET Microwaves Antennas \& Propagation, Progress in Electromagnetics Research (PIER), and AEÜ International Journal of Electronics and Communications. Dr. Mandal is a senior member of IEEE. 